\title{
Corrigendum: Functional labeling of neurons and their projections using the synthetic activity-dependent promoter E-SARE
}

Takashi Kawashima, Kazuo Kitamura, Kanzo Suzuki, Mio Nonaka, Satoshi Kamijo, Sayaka Takemoto-Kimura, Masanobu Kano, Hiroyuki Okuno, Kenichi Ohki \& Haruhiko Bito

Nature Methods 10, 889-895 (2013); published online 14 July 2013; corrected after print 19 September 2013

In the version of this article initially published, the schema shown in Figure 5a was wrong. The error has been corrected in the HTML and PDF versions of the article.

\section{Corrigendum: Accounting for technical noise in single-cell RNA-seq experiments}

Philip Brennecke, Simon Anders, Jong Kyoung Kim, Aleksandra A Kołodziejczyk, Xiuwei Zhang, Valentina Proserpio, Bianka Baying, Vladimir Benes, Sarah A Teichmann, John C Marioni \& Marcus G Heisler

Nat. Methods; doi:10.1038/nmeth.2645; corrected after print 11 October 2013

In the version of this article initially published online, the dilution for the ERCC Spike-In Control Mix added to the lysis mix was given as 1:40,000 in the Online Methods. The actual dilution used was 1:400. The error has been corrected for the PDF and HTML versions of this article.

\section{Erratum: Adding an unnatural covalent bond to proteins through proximity-enhanced bioreactivity}

Zheng Xiang, Haiyan Ren, Ying S Hu, Irene Coin, Jing Wei, Hu Cang \& Lei Wang

Nat. Methods 10, 885-888 (2013); published online 4 August 2013; corrected after print 21 November 2013

In the version of this article initially published, in Figure $2 \mathrm{e}$, lanes 6 and 8 should have been labeled " $F_{\text {act }}$ " not " $F_{\text {fact }}$ " In the legend for this figure, the sentence "N3 indicates cysteine..." should have read "C3 indicates cysteine...." The errors have been corrected in the HTML and PDF versions of the article.

\section{Erratum: Power and sample size}

Martin Krzywinski \& Naomi Altman

Nat. Methods 10, 1139-1140 (2013); published online 26 November 2013; corrected after print 26 November 2013

In the print version of this article initially published, the symbol $\mu_{0}$ was represented incorrectly in the equation for effect size, $d=\left(\mu_{\mathrm{A}}-\mu_{0}\right) / \sigma$. The error has been corrected in the HTML and PDF versions of the article.

\section{Corrigendum: Comparative analysis of RNA sequencing methods for degraded or low-input samples}

Xian Adiconis, Diego Borges-Rivera, Rahul Satija, David S DeLuca, Michele A Busby, Aaron M Berlin, Andrey Sivachenko, Dawn Anne Thompson, Alec Wysoker, Timothy Fennell, Andreas Gnirke, Nathalie Pochet, Aviv Regev \& Joshua Z Levin

Nat. Methods 10, 623-629 (2013); published online 19 May 2013; corrected after 2 December 2013

In the version of this article initially published, in the Online Methods "RNase H libraries" section, the sentence beginning with "We added $5 \mu$ l preheated RNase H..." should have read "We added $5 \mu$ l preheated RNase $\mathrm{H}$ reaction mix that contains $10 \mathrm{U}$ of Hybridase Thermostable RNase $\mathrm{H}$ (Epicentre), $0.5 \mu \mathrm{mol}$ Tris- $\mathrm{HCl}, \mathrm{pH} 7.5,1 \mu \mathrm{mol} \mathrm{NaCl}$ and $0.2 \mu \mathrm{mol} \mathrm{MgCl}_{2}$ to the RNA and DNA oligo mix, incubated this mixture at $45^{\circ} \mathrm{C}$ for $30 \mathrm{~min}$ and then placed it on ice." The errors have been corrected in the HTML and PDF versions of this article. 